\title{
SIZE DEPENDENT EFFECTS ON FRACTURE TOUGHNESS OF CONCRETE
}

P. Nallathambi and B. L. Karihaloo

Department of Civil Engineering and Surveying, University of Newcastle, NSW 2308, Australia

ABSTRACT

The paper reports the results of a series of three-point bend tests on concrete beams. The tests were performed with a view to studying the influence of pre-crack, aggregate and specimen sizes on the fracture energy of concrete. A simple formula based on the experimental data is proposed to account for all the three size dependent effects. Other parameters having a significant influence on the fracture of concrete are also pointed out.

\section{KEYWORDS}

Fracture of concrete; Energy release rate; Direct and Indirect methods of measurement; Size of specimens; Size of coarse aggregate; Depth of premeasurement; Size of specimens; Size of coarse aggregate; Depth

\section{INTRODUCTION}

Many attempts have been made in the past to apply the theory of linear elastic fracture mechanics (LEFM) to characterize the fracture behaviour of cementitious materials. However, in view of the wide variety of factors which can influence this behaviour, it is hardly surprising that the results reported in the literature have at times been contradictory and confusing. reported in the literature have at times been contradictory and confusing. The factors that are most likely to influence the fracture behaviour of of coarse aggregate (Swamy and Rao 1973, Waish 1976, Higgins and Bailey 1976), water-cement ratio, curing time and porosity (Shah and McGarry 1971, Brown and Pomeroy 1973). Besides these there are other parameters which have been shown to have a marked effect on the results of fracture toughness tests. Among these parameters are the size of the test specimens and of any pre-

It is well known that concrete exhibits a non-linear load-deflection behaviour because of its heterogeneous composition and of the formation of micro-cracks during loading. It is therefore not surprising that past attempts at describing this behaviour using LEFM have not been very successful. The two 
most commonly used parameters in LEFM for homogeneous brittle materials the critical stress intensity factor $\left(K_{C}\right)$ and the critical energy release rate $\left(G_{C}\right)$, together with their plane stress/plane strain relationship ship an indirect method for determining $K_{C}$ and $G$. Based on this relationthis method, a pre-cracked specimen of known $K_{C} G_{C}$ as is at failure recorded to $c a l c u l a t e ~ G ⿰ 亻$ stress field at the crack-tip at the onset of fracture. valid, if the crack-tip process zone is small in relation to the specimen size. For concrete, in which the micro-cracked zone ahead of the pre-crack is analogous to the plastic zone in metals, this would require that the pre crack length be in excess of $200 \mathrm{~mm}$ (Walsh 1972) making the resulting specimen dimensions very impractical.

Movenzadeh and Kuguel (1969), Harris and Varlow (1972), and Radjy and Hanson (1973) have proposed another (direct) method for determining the fracture characteristics of brittle materials. The concept of Griffith surface energy has been extended to materials which are accompanied by substantial energy dissipation at the crack-tip. In this method, the area per unit cross-section under a stable load-deflection plot of a three-point bend specimen is taken to represent the fracture energy of concrete. For an ideal linear elastic material the respective values of $G_{C}$ and $K_{C}$ determined by both the methods are equal. But for materials, such as concrete, in which substantial energy dissipation occurs at the crack-tip due to micro-cracking, debonding at matrix-aggregate interface, crack arresting by coarse aggregate particles and crack jumping around air-voids, the two methods give considerably different values. However, as Visalvanich and Naaman (1981) have pointed out, the direct energy method because it records the total energy spent in creating new crack surfaces should give an improved estimate of the true fracture toughness of concretes. A detailed comparison of the two methods was reported by Petersson (1980a).

It was the aim of the present investigation to study the influence of precrack, maximum aggregate and specimen sizes on the fracture toughness of concrete with a view to proposing a simple functional relationship between them. It should be mentioned that other parameters, such as the type of agregate and water-cement ratio, were kept constant. All the tests wer both the direct and indirect methods.

\section{AND SPECIMEN PREPARATION}

Table 1 shows the overall dimensions of some of the test beams. The pre-crack (notch) depth as a proportion of the depth of the beam was varied between 0 (unnotched) and 0.7 in steps of 0.1 . The maximum size of the coarse aggregate which in turn depends on the size of the mixes are designated according to the maximum size of the coarse aggregate. Thus, in what follows we will refer to $20 \mathrm{~mm}, 14 \mathrm{~mm}$ and $10 \mathrm{~mm}$ mixes mixes were also used. The mixes were designed in such a way that with a constant water-cement ratio (0.5), the cylinder compressive strength was reasonably constant regardless of the maximum aggregate size. This led to the mix composition shown in Table 2. Rounded river gravel and ordinary portland cement were used in all mixes.

The test beams were cast in steel moulds with wooden bases. The pre-crack (notch) was introduced using a shim made up of a razor blade stiffened by brass strips. This method was found in the later stages of experimentation following wear and distortion to result occasionally in premature cracking of specimens during the withdrawal of the shim. It was therefore thought desirable to introduce the sharp notch by a $6 \mathrm{~mm}$ thick mild steel strip milled to a very sharp edge. The edge was remilled as often as necessary to retain its sharpness. The concrete was poured and vibrated with the shim/ steel wedge in position. To reduce the occurrence of precracking during stripping the shim/wedge was gently pulled out from the test specimen after the initial setting time (approximately seven hours). The beams were stripped after twenty four hours and placed inside a fog chamber for curing. Two These were used to determine the compressive strength and elastic modulus of the mix.

TABLE 1 Specimen Dimensions and Mix Designation

\begin{tabular}{|c|c|c|c|c|}
\hline \multirow{2}{*}{$\begin{array}{c}\text { Test Group } \\
\text { Number }\end{array}$} & \multicolumn{3}{|c|}{ Specimen Dimensions, mm } & Mix Designation \\
\cline { 2 - 4 } & Span & Width & Depth & 20 \\
\hline \hline 1 & 600 & 80 & 152 & 20 \\
2 & 600 & 80 & 127 & 20 \\
3 & 600 & 80 & 102 & 20 \\
4 & 600 & 80 & 76 & 14 \\
5 & 600 & 80 & 76 & 10 \\
6 & 600 & 80 & 76 & 5 \\
7 & 600 & 80 & 76 & 2 \\
8 & 600 & 80 & 76 & 14 \\
9 & 400 & 55 & 127 & 14 \\
10 & 400 & 55 & 102 & 14 \\
11 & 400 & 55 & 76 & 14 \\
12 & 400 & 55 & 64 & 10 \\
13 & 400 & 55 & 64 & 5 \\
14 & 400 & 55 & 64 & 2 \\
15 & 400 & 55 & 64 & 10 \\
16 & 200 & 40 & 102 & 10 \\
17 & 200 & 40 & 76 & 10 \\
18 & 200 & 40 & 64 & 5 \\
19 & 200 & 40 & 51 & 2 \\
20 & 200 & 40 & 51 & \\
21 & 200 & 40 & 51 & \\
& & & & \\
\end{tabular}

TABLE 2 Mix Proportions $\mathrm{kg} / \mathrm{m}^{3}$

\begin{tabular}{|l|r|r|r|r|c|}
\cline { 2 - 6 } & $20 \mathrm{~mm}$ & $14 \mathrm{~mm}$ & $10 \mathrm{~mm}$ & $5 \mathrm{~mm}$ & Mortar $(2 \mathrm{~mm})$ \\
\hline $\begin{array}{l}\text { Combined } \\
\text { Aggregate }\end{array}$ & 1674 & 1673 & 1650 & 1618 & 1336 \\
\hline Cement & 384 & 385 & 396 & 411 & 547 \\
\hline Water & 192 & 192 & 198 & 206 & 274 \\
\hline Yield & 2250 & 2250 & 2245 & 2235 & 2155 \\
\hline Slump, mm & 75 & 70 & 65 & 45 & 80 \\
\hline
\end{tabular}


TEST PROCEDURE

The specimens were removed from the fog chamber on the twenty-eighth day of curing and tested in the wet state in a displacement rate controlled machine The loading arrangement for the three-point bend test is shown in Fig. 1.

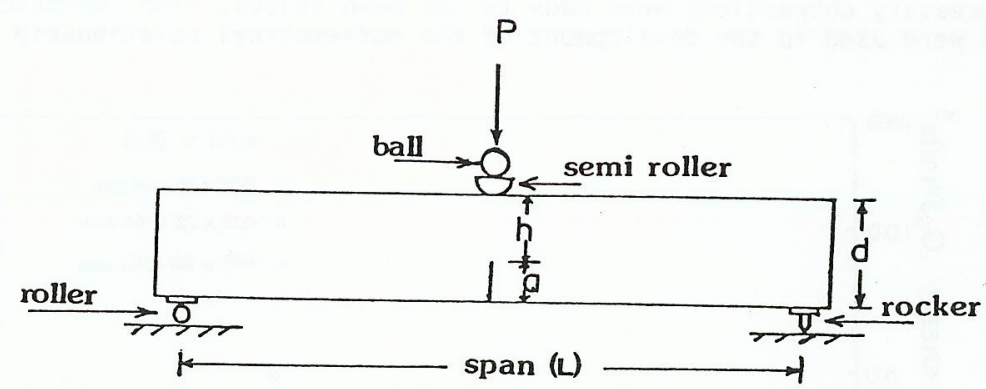

Fig. 1. Loading Arrangement

The load was measured by an electrical load cell (calibrated to take account of the specimen self-weight) and the deflection by a linearly varying displacement transducer (LVDT). The point at which the deflection was measured was adjacent to the notch at midspan. The LVDT was held in such a position that the measured value represented the true deflection of the neutral axis of the beam thus excluding the influence of any crushing at the supports or under the load. The outputs from the load cell and LVDT were coupled through an X-Y recorder to obtain the load-deflection plot of the test specimen. The cross head speed was adjusted so that the maximum load was achieved in about 60 seconds. By controlling the cross-head speed it was also possible to record a stable load-deflection curve after the maximum load. A typical loaddeflection plot is shown in Fig. 2 .

The maximum load $\left(P_{\max }\right.$ ) needed in the calculation of $K_{C}$ and $G_{C}$ by the indirect method was read off the load-deflection curve. On the other hand, to calculate the energy release rate $G_{c}$ by the direct method, the area under the load-deflection curve was measured using a planimeter. The elastic modulus $(E)$ and compressive strength $\left(\sigma_{C}\right)$ of the mix were determined from separate cylinder tests.

\section{RESULTS AND DISCUSSION}

Figure 3 shows the variation of the energy release rate, $G_{C}$, with notch-depth for $20 \mathrm{~mm}$ mix as obtained by the direct and indirect methods of calculation.

The energy release rate calculated by the direct method varies between 40 and $130 \mathrm{~J} / \mathrm{m}^{2}$, and between 3 and $18 \mathrm{~J} / \mathrm{m}^{2}$ when calculated by the indirect method. The results obtained by the direct method are in good agreement with those method are in reasonable energy release rates obtained by the two methods show a similar trend as far as the specimen size is concerned it would seds show a similar trend as far underestimates the true fracture toughess of concrete. This is method this method no consideration is given to the damage processes (micro-cracking,

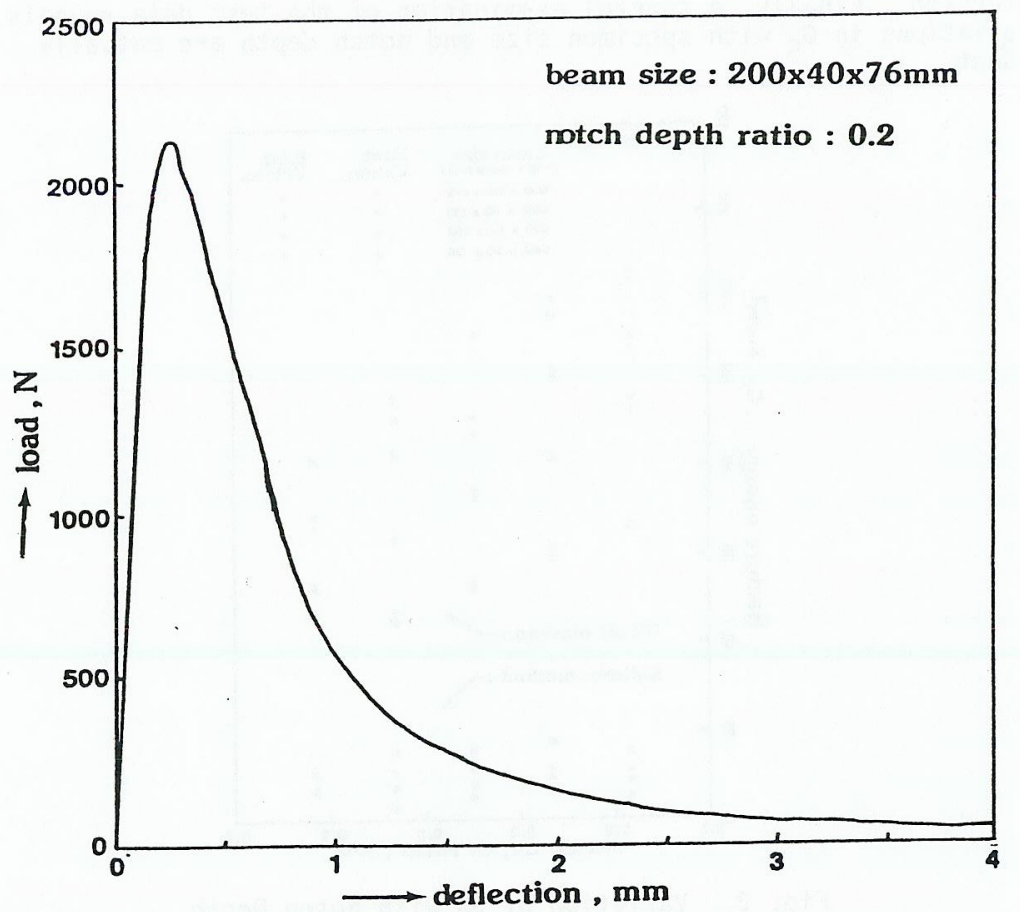

Fig. 2. Typical Load - Deflection Curve

debonding and crack arresting) taking place in the fracture zone and clearly debonding and crack arresting) tak ing place method however allows for the energy dissipated during crack propagation due to the various mechanisms mentioned above; the dissipated energy is an order of magnitude greater than the elastic strain energy of concrete. As a result, it seems reasonable to conclude that the fracture toughness determined by the indirect method does not represent the true fracture toughness of concrete. The fracture toughness estimate by the direct method is more reliable. It should however be mentioned that the direct method could well over-estimate slightly the fracture toughness because it does not allow for any energy spent outside the fracture zone. However, since the crack propogated generally in line with the pre-crack this energy cannot be very large. Further experimentation and finite element calculations are in progress to resolve the doubt. These will be reported during the presentation of the paper.

In order to get a clearer picture of the various size dependent effects in the fracture process, Figure 4 shows the energy release rate $G_{c}$ as a function of specimen volume for a typical notch depth. It is evident that $G_{C}$ decreases with increasing specimen size. It is also clear that (Fig. 5) that $\mathrm{G}_{c}$

increases with increasing maximum aggregate size. The latter observation does not support the results reported by Petersson (1980b). This may be attributed to the inadequate number of the maximum aggregate sizes studied 
by Petersson. Finally, a careful examination of the test data reveals that the variations in $G_{C}$ with specimen size and notch depth are mutually

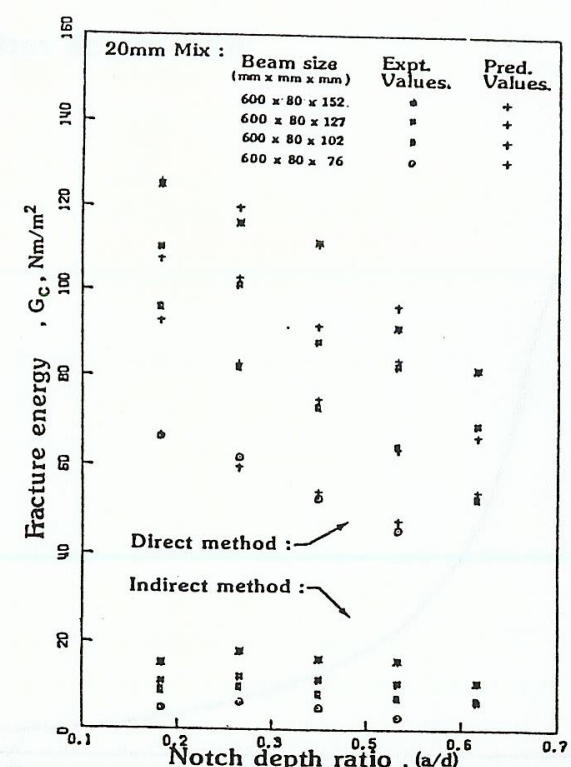

Fig. 3. Variation of $G_{C}$ with Notch Depth Ratio for Different Beam Sizes

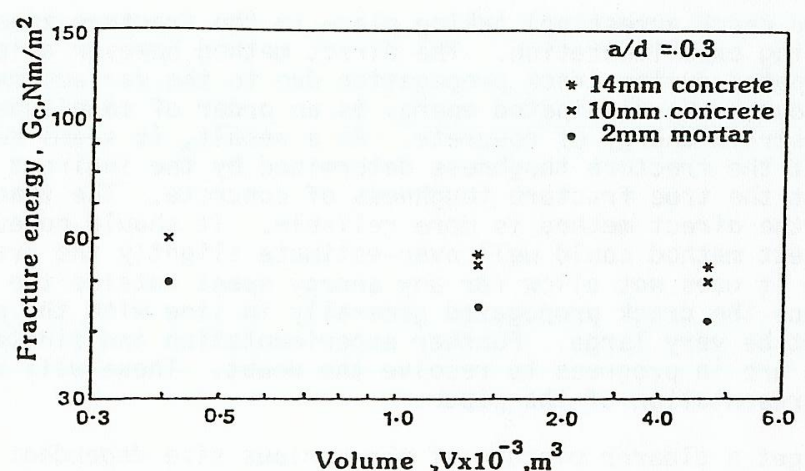

Fig. 4. Variation of $G_{C}$ with Volume
STATISTICAL ANALYSIS OF TEST RESULTS

The mean values shown in Fig. 3-5 were calculated from the $G_{c}$ values determined individually for each specimen. In each group of tests (Table 1) a maximum of six specimens were tested. Assuming student distribution the significance level of each test result in any particular group was tested and necessary corrections were made to the mean values. The corrected mean values were used in the development of the mathematical relationship described below.

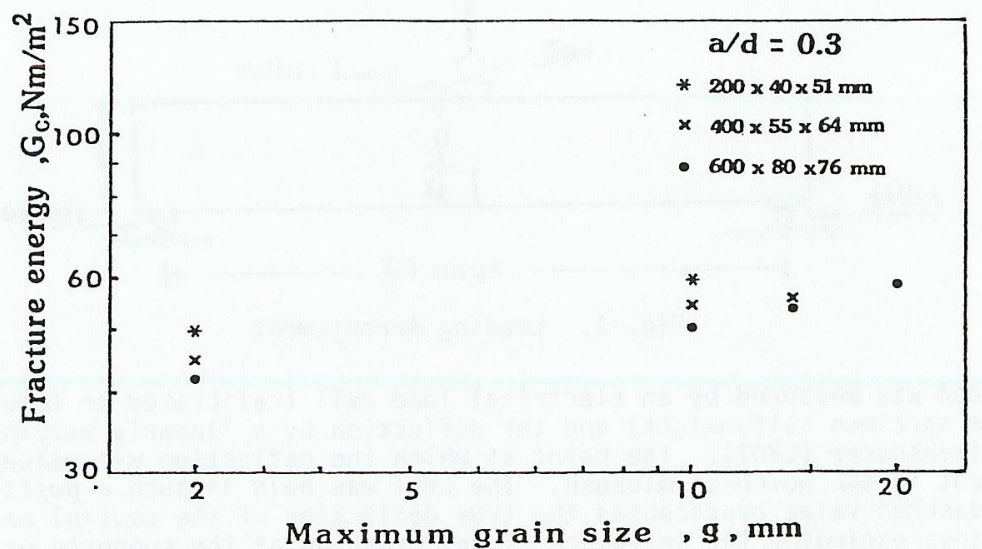

Fig. 5. Variation of $G_{C}$ with

From a careful examination of the whole test record (only sample graphs are shown in Fig. 3-5), it was observed that $G_{c}$ increased with increasing maximum aggregate size and depth to span ratio, but decreased with increasing notch depth. Moreover, there was a definite interdependence between the latter two size parameters. With these observations in mind, the following non-linear relationship was tried:

$$
G_{C}^{*}=\alpha_{1}\left(\frac{g}{b}\right)^{\alpha_{2}}\left(\frac{d}{L}\right)^{\alpha_{3}+\alpha_{4}\left(\frac{a}{d}\right)},
$$

where the non-dimensional energy release rate $G_{C}^{*}$ is given by

$$
G_{C}^{*}=G_{c} /\left(\sigma_{c}^{2} b / E\right)
$$

Here, $\sigma_{c}(\mathrm{~Pa})$ and $E(\mathrm{~Pa})$ are the compressive strength and Young's modulus of the mix as determined by the cylinder tests; $d$, $b$ and $L$ are respectively of the mix as a decimum size of the coarse aggregate and a the notch-depth.

The procedure used to determine the constants $\alpha_{j}(i=1,4)$ from the experimental data was based on the method of least squares using a nonlinear regression analysis (Draper and Smith 1966). The best fit was obtained when $\alpha_{1}=0.1431, \alpha_{2}=0.1713, \alpha_{3}=0.7666$ and $\alpha_{4}=0.4154$. 


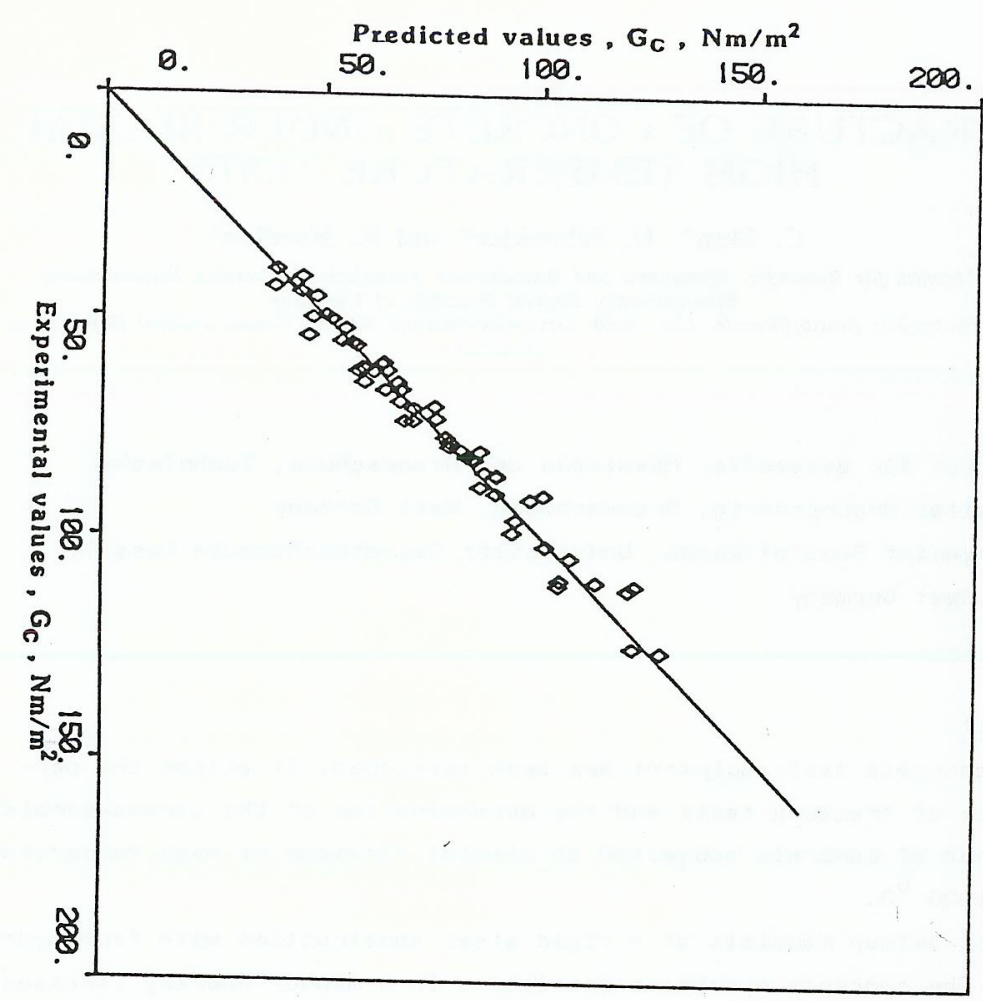

Fig. 6. Comparison of Predicted Equation with Experimental Results

To get an idea of the validity of the proposed relationship, the experimental values of $G_{C}$ are plotted against the predicted values in Fig. 6 . It is clear stressed sizes for that the predictions may be less so outside the range of the various investigation is in prmental data was available. Further experimental proposed formula propos formula and to verify whether $G_{c}$ achieves an asymptotic value at the paper.

\section{CONCLUSIONS}

1. The direct method of determining the critical energy release rate, $G_{C}$ of concrete seems to be more appropriate than the indirect method, although further theoretical evidence is needed to justify this claim.

2. The critical energy release rate increases with increasing maximum coarse aggregate size and depth to span ratio, but decreases with increasing pre-crack size. Moreover, the latter two size effects show a marked interdependence.

3. The dependence of critical energy release rate on the three size parameters is accurately predicted by the following mathematical relationship:

$$
G_{c}=0.1413\left(\frac{{ }^{\circ}{ }^{2} b}{E}\right)\left(\frac{g}{b}\right) \quad\left(\frac{d}{L}\right){ }^{0.1713} 0.7666+0.4154\left(\frac{a}{d}\right)
$$

4. Further experimental and theoretical investigation is in progress to establish the range of validity of the above equation and to verify whether $G_{C}$ achieves an asymptotic value at large $d$ and $a / d$, as has been suggested by some researchers.

\section{ACKNOWLEDGEMENT}

The experimental investigation reported here was supported by a grant (F 8015819) to B.L. Karihaloo from the Australian Research Grants Scheme. It is a pleasure to acknowledge Mr. B.S. Heaton's assistance with mix designs.

\section{REFERENCES}

Brown, J.M., and C.D. Pomeroy, (1973). Cement and Concrete Research, 3, $475-480$.

Draper, N.R., and H. Smith, (1966). Applied Regression Analysis, John Wiley \& Sons, Inc. N.Y.

Harris, B. and J. Varlow, (1972). Cement and Concrete Research, 2, $447-461$.

Higgins, D.D., and J.E. Bailey, (1976). Journal of Materials Science, 11, 1995 - 2003.

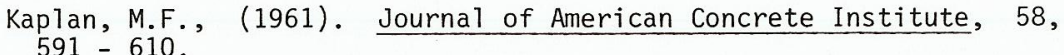
Movezadeh, F., and R. Kugel, (1969). Journal of Materials, JMLSA, 4, $497-519$.

Petersson, P.E., (1980a). Cement and Concrete Research, 10, 78 - 79. Petersson, P.E., (1980b). Cement and Concrete Research, 10, 91 - 101. Radjy, F., and T.C. Hanson, (1973). Cement and Concrete Research, 3 , $343-361$

Shah, S.P., and F.J. McGarry, (1971). J.Eng.Mech.Div., ASCE, 97, $1663-1676$

Stock, A.F., Hannant, D.J. and R.I.T. Williams, (1979). Magazine of Concrete Research, $31,225-234$ 

Strange, P.C., and A.H. Bryant, (1979a). Journal of Materials Science,

Strange, P.C., and A.H. Bryant, (1979b). J. Eng. Mech. Div., ASCE, $105,337-342$

Swamy, R.N., and C.V.S. Rao, (1973). Cement and Concrete Research,

Visalvanich, K., and A.E. Naaman, (1981). J. Eng. Mech. Div., ASCE, $107,1155-1171$

Walsh, P.F., (1972). Indian Concrete Journal, 46, 469 - 476.

Walsh, P.F., (1976). Magazine of Concrete Research, 28, $37-41$. 